\title{
Impaired Cardiac Sympathetic Nerve Function in Patients with Kawasaki Disease: Comparison with Myocardial Perfusion
}

\author{
CHUNLEI ZHAO, NORIYUKI SHUKE, WAKAKO YAMAMOTO, ATSUTAKA OKIZAKI, \\ JUNICHI SATO, HIROKI KAJINO, KENJI FUJIEDA, AND TAMIO ABURANO \\ Departments of Radiology [C.Z., N.S., W.Y., A.O., T.A.] and Pediatrics [H.K., K.F.], Asahikawa Medical \\ College; and Section of Radiology [J.S.], Asahikawa Medical College Hospital, Asahikawa, 078-8510, \\ Japan; Department of Nuclear Medicine, the Second Affiliated Hospital, Medical College of Zhejiang \\ University, Hangzhou, 310009, China [C.Z.]
}

\begin{abstract}
Kawasaki disease (KD) is a leading cause of CAD in children. The impairment of cardiac sympathetic nerve function (CSNF) in the adult patients with coronary artery disease (CAD) could often be seen. However, little is known concerning the impairment of CSNF in KD patients. We investigated CSNF and its relationship with myocardial perfusion in KD patients. Eleven children with $\mathrm{KD}$ and 4 controls were studied with ${ }^{123}$ I-metaiodobenzylguanidine (MIBG) and stressed ${ }^{201} \mathrm{Tl}$ single photon emission computed tomography. By the findings on coronary artery angiography (CAG), the patients were divided into 2 groups: A, without stenosis; B, with significant stenosis and/or old myocardial infarction. CSNF was evaluated from the uptake of ${ }^{123} \mathrm{I}-\mathrm{MIBG}$. While myocardial perfusion was evaluated from ${ }^{201} \mathrm{Tl}$ uptake. The numbers of patients in the groups A and B were 7 and 4 . Perfusion defect was found in 0 , and 2 patients in group $\mathrm{A}(0 \%)$, and B $(50 \%)$. ${ }^{123} \mathrm{I}-\mathrm{MIBG}$ defects were found in 1 and 4 patients in the group A (14\%) and B (100\%). There were excellent concordances between the finding of ${ }^{201} \mathrm{Tl}$ and ${ }^{123} \mathrm{I}-\mathrm{MIBG}$ in
\end{abstract}

\section{ABSTRACT}

group A. While in group $\mathrm{B}$, the coronary territories with ${ }^{123} \mathrm{I}-$ MIBG defects were significantly more than those with perfusion defects $(p<0.05)$. In KD patients, the impairment of CSNF might be subsequent to coronary artery stenosis and was more severe than the injury of myocardial perfusion. (Pediatr Res 57: 744-748, 2005)
Abbreviations
CAD, coronary artery disease
CAG, coronary artery angiography
CSNF, cardiac sympathetic nerve function
FWHM, full width of half maximum
KD, Kawasaki disease
$\mathbf{L V}$, left ventricle
MIBG, metaiodobenzylguanidine
NE, norepinephrine
SPECT, single photon emission computed tomography

Kawasaki disease (KD) is a syndrome of children and occasionally young adults, manifested by a distinctive erythematous and desquamative exanthem, conjunctivitis, fever, and acute vasculitis mainly affecting small- and medium-sized arteries, particularly the coronary arteries $(1,2)$. It is one of the main causes of coronary heart disease in children (3). Extensive cardiac involvement may cause sudden death as a result of myocardial infarction $(4,5)$. However, children with significant coronary involvement as a result of $\mathrm{KD}$ are generally asymptomatic despite significant risk for myocardial infarction $(6,7)$. Therefore, it is crucial to follow up and detect coronary artery involvement in a timely manner in the KD patient. Coronary

Received February 6, 2004; accepted September 3, 2004.

Correspondence: Chunlei Zhao, M.D., Department of Nuclear Medicine, The Second Affiliated Hospital, Medical College of Zhejiang University, No. 88, Jie Fang Road, Hangzhou, 310009, China. Email: zhaocl@asahikawa-med.ac.jp

DOI: 10.1203/01.PDR.0000156511.03924.9F artery angiography (CAG) is usually performed to evaluate the involvement of coronary artery. However, CAG cannot assess the physiologic status such as the involvement of myocardial ischemia or infarction (8), although it is an accurate method for obtaining anatomic details of large- and medium-sized coronary arteries (9). For evaluating myocardial perfusion, ${ }^{201} \mathrm{Tl}$ and ${ }^{99 \mathrm{~m}}$ Tc-labeled perfusion tracers have been applied in the patients with KD (10-15). Compared with CAG, perfusion studies could detect perfusion defects even in the absence of coronary abnormalities $(1,16,17)$ and seemed to be useful for making decisions on coronary artery bypass surgery and for predicting the prognosis in $\mathrm{KD}$ patients as well $(15,18)$.

Metaiodobenzylguanidine (MIBG) is a structure analog of norepinephrine (NE) and has the same uptake and storage mechanisms as NE has (19). MIBG is stored in presynaptic vesicles and is secreted in response to acetylcholine released from the preganglionic neuron $(20,21)$. MIBG labeled with ${ }^{123}$ I 
has been generally accepted for assessing cardiac sympathetic nerve function (CSNF) in many diseases, such as coronary artery disease (CAD), heart failure, diabetes, Parkinson's disease, and cardiomyopathy (22-27). In these diseases, decreased cardiac ${ }^{123}$ I-MIBG uptake was thought to reflect sympathetic denervation. In adult patients with CAD, CSNF impairment could often be seen (28-31). Generally, the areas of reduced MIBG uptake are larger than perfusion defects in myocardial infarction (29-31), indicating that the areas of sympathetic denervation not only were limited to the necrotic zones but also extended to noninfarcted myocardium $(29,31)$; such lesions are considered to be viable but denervated (30). In patients with $\mathrm{KD}$, although coronary artery is frequently involved, little is known concerning the injury of CSNF. Therefore, we carried out the present study to investigate CSNF and to clarify its relationship with the involvement of coronary artery in patients with KD.

\section{METHODS}

Patients. Eleven children with KD (nine boys, two girls; age, $8.6 \pm 6.1 \mathrm{y}$; range, $0.5-16.1$ y) were studied with ${ }^{123} \mathrm{I}-\mathrm{MIBG}$ and stressed ${ }^{201} \mathrm{Tl}$ (either exercise or dipyridamole stress) single-photon emission computed tomography (SPECT) within 2 wk without any medical intervention. Their histories of KD ranged from 0.2 to 14.5 y $(6.1 \pm 6.4$ y). Four age-matched children $(9.5 \pm$ $6.2 \mathrm{y}$; range, 4.2-16.3 y), among which three had acute lymphocyte leukemia without myocardial impairment after chemotherapy and one had glycogen storage disease (type IX), were examined with both imaging techniques and served as control subjects. None of the control subjects had chest pain or abnormal finding in ECG. The hospital ethical committee approved the study, and all of the children or their parents gave informed consent before the study.

According to the finding of CAG and the history, patients were classified into two groups. Group A comprised the patients without present or past coronary artery stenosis; group B comprised the patients with significant coronary artery stenosis and/or history of myocardial infarction.

By referring to the nomenclature of standardized myocardial segmentation for tomographic imaging by the American Heart Association (32), left ventricle (LV) was divided into three coronary territories corresponding to left anterior descending branch, left circumflex branch, and right coronary artery as shown in Fig. 1.

Coronary angiography. Coronary angiography was performed within $1 \mathrm{mo}$ of ${ }^{201} \mathrm{Tl}$ and ${ }^{123} \mathrm{I}-\mathrm{MIBG}$ imaging in 10 patients and within $1 \mathrm{y}$ in one patient. A coronary aneurysm was defined when the diameter of the coronary artery was 1.5 times greater than that of the adjacent vessel. Slight dilation of the coronary artery less than this criterion was considered as normal. Significant coronary artery stenosis was defined as $\geq 75 \%$ stenosis of the coronary artery lumen.

Imaging protocol. For both ${ }^{201} \mathrm{Tl}$ and ${ }^{123} \mathrm{I}-\mathrm{MIBG}$ imaging, data were obtained using a single-headed rotating gamma camera equipped with a low-energy general-purpose collimator (RC-135E; Hitachimedico, Tokyo, Japan). The full width of half maximum (FWHM) of this system is $9.6 \mathrm{~mm}$ for

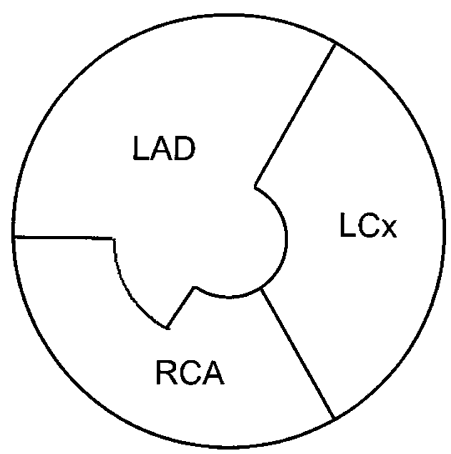

Figure 1. Diagram of coronary territories of LV on short axial plane. LAD, left anterior descending branch; LCx, left circumflex branch; RCA, right coronary artery. 100-mm radius of rotation in the air. All patients fasted on the day of study and continued to fast until the study was completed.

In the ${ }^{123} \mathrm{I}-\mathrm{MIBG}$ study, $1.85 \mathrm{MBq} / \mathrm{kg}{ }^{123} \mathrm{I}-\mathrm{MIBG}$ (MyoMIBG-I-123, 111 MBq/0.03-0.10 mg; Daiichi Radioisotope Laboratory, Tokyo, Japan) was injected i.v.. With this tracer, the absorbed dose in organs of a 5 -y-old child is $0.055 \mathrm{mGy} / \mathrm{MBq}$ in heart, 0.18 in liver, 0.036 in kidneys, 0.018 in testes, and 0.025 in ovaries, and the effective dose is $0.037 \mathrm{mSv} / \mathrm{MBq}$ (33). Early imaging began at $15 \mathrm{~min}$ after the injection. Thirty-two projections were obtained on a $64 \times 64$ matrix for $40 \mathrm{~s}$, with a 180-degree rotation and an energy window of $10 \%$ centered at $160 \mathrm{KeV}$. Four hours later, delayed imaging was performed under the same acquisition conditions as used in the early imaging.

Exercise-stress ${ }^{201} \mathrm{Tl}$ imaging was performed in seven patients using an exercise protocol. Patients performed exercise on a bicycle ergometer (BE-360 Well Bike; Fukuda Denshi, Tokyo, Japan), which started at $50 \mathrm{~W}$ and successively increased by $25 \mathrm{~W}$ every 3 min until the occurrence of fatigue or reaching $\geq 85 \%$ age-predicted heart rate. Six patients fulfilled the exercise testing, and one patient was terminated for the occurrence of ventricular tachycardia. At $1 \mathrm{~min}$ before the termination of the exercise, $1.85 \mathrm{MBq} / \mathrm{kg}$ ${ }^{201} \mathrm{Tl}$ (Thallium Chloride-201; Daiichi Radioisotope Laboratory) was injected i.v.. With this tracer, the absorbed dose in organs of a 5 -y-old child is 0.62 $\mathrm{mGy} / \mathrm{MBq}$ in heart, 0.45 in liver, 1.2 in kidneys, 9.6 in testis, and 3.5 in ovary, and the effective dose is $1.7 \mathrm{mSv} / \mathrm{MBq}$ (33). At $15 \mathrm{~min}$ after the injection, 32 projections were obtained on a $64 \times 64$ matrix for $30 \mathrm{~s}$, with a 180-degree rotation and an energy window of $20 \%$ centered at $70 \mathrm{KeV}$. The rest ${ }^{201} \mathrm{Tl}$ imaging was performed at $4 \mathrm{~h}$ after the injection using the same acquisition conditions as used in the stress study. For four patients, including three infantile patients who were unable to undergo the exercise-stress, dipyridamole was administrated i.v. for $4 \mathrm{~min}$ with a dose of $0.56 \mathrm{mg} / \mathrm{kg}$. The 12-lead ECG was recorded at 1-min intervals throughout the infusion. Three minutes after dipyridamole infusion, $1.85 \mathrm{MBq} / \mathrm{kg}{ }^{201} \mathrm{Tl}$ was given. Stress imaging was performed at $15 \mathrm{~min}$ after injection, and rest imaging was performed $4 \mathrm{~h}$ later with the same acquisition conditions as used in the exercise-stressed study.

Image reconstruction was performed by a filtered back projection algorithm without attenuation correction and scatter correction for both ${ }^{123} \mathrm{I}-\mathrm{MIBG}$ and

${ }^{201} \mathrm{Tl}$ studies. After preprocessing with a Butterworth filter (cutoff frequency, $0.44 \mathrm{cycle} / \mathrm{cm}$; order, 8), transaxial images were reconstructed with a ramp filter. Long- and short-axial slices then were produced by axial reorientation.

Data analysis. Uptake of ${ }^{201} \mathrm{Tl}$ and ${ }^{123} \mathrm{I}-\mathrm{MIBG}$ was evaluated from tomographic images by two experienced observers for the three coronary territories by referring to the quantitative color scale setting the highest uptake of LV as $100 \%$. In both studies, an uptake $\geq 60 \%$ of the highest uptake of LV was defined as within the normal range. In either early or delayed ${ }^{123} \mathrm{I}-\mathrm{MIBG}$ studies, ${ }^{123}$ I-MIBG defect was defined as an uptake $<60 \%$ of the highest uptake of LV. In stressed and rest ${ }^{201} \mathrm{Tl}$ imaging, myocardial ischemia was defined as an uptake $<60 \%$ of the highest uptake of LV in stressed study but $\geq 60 \%$ of the highest uptake of LV in rest study, whereas myocardial damage was defined as an uptake $<60 \%$ of the highest uptake of LV in both stressed and rest studies. Both myocardial ischemia and damage were defined as perfusion defect. The coronary territories with perfusion defect and ${ }^{123}$ I-MIBG defect were counted for every patient.

Statistical analysis. The concordance between the coronary territories with ${ }^{123} \mathrm{I}-\mathrm{MIBG}$ defects and those with perfusion defects in the patients was investigated by McNemar's test. A $p<0.05$ was considered statistically significant.

\section{RESULTS}

No perfusion and ${ }^{123} \mathrm{I}-\mathrm{MIBG}$ defect was found in control subjects. The clinical and imaging information of the patients are listed in Table 1. Groups A and B consisted of seven and four patients, respectively. Three patients in group B had histories of myocardial infarction. Myocardial perfusion defect was found in zero $(0 \%)$ and two $(50 \%)$ patients in groups $\mathrm{A}$ and $\mathrm{B}$, respectively, whereas ${ }^{123} \mathrm{I}-\mathrm{MIBG}$ defects were found in one $(14.3 \%)$ patient in group A and four (100\%) patients in group B. Among 12 coronary territories in group B, seven had stenosis and/or histories of myocardial infarction. All seven of these coronary territories had ${ }^{123} \mathrm{I}-\mathrm{MIBG}$ defects, whereas perfusion defect was found only in three of them. Among the left five coronary territories with normal coronary artery or with aneurysm alone in group B, two had ${ }^{123}$ I-MIBG defects and none had myocardial perfusion defect. 
Table 1. Angiography, ${ }^{123} I-M I B G$, and ${ }^{201}$ TI SPECT data in the patients with KD

\begin{tabular}{|c|c|c|c|c|c|c|c|c|}
\hline Case & Sex & $\begin{array}{c}\text { Age at } \\
\text { study (y) }\end{array}$ & $\begin{array}{l}\text { History of } \\
\mathrm{KD}(\mathrm{y})\end{array}$ & \multicolumn{3}{|c|}{ Lesions in coronary angiography } & $\begin{array}{c}\text { CT with Defects in } \\
\text { E\&D }{ }^{123} \text { I-MIBG } \\
\text { SPECT }\end{array}$ & $\begin{array}{l}\text { CT with PD } \\
\text { in }{ }^{201} \mathrm{TI} \\
\text { SPECT }\end{array}$ \\
\hline \multicolumn{9}{|c|}{ Group A } \\
\hline 2 & $\mathrm{~F}$ & 1.4 & 0.3 & $\mathrm{~N}$ & $\mathrm{~N}$ & $\mathrm{~N}$ & - & - \\
\hline 3 & M & 0.5 & 0.2 & $\mathrm{~N}$ & $\mathrm{~N}$ & $\mathrm{~N}$ & - & - \\
\hline 4 & $\mathrm{~F}$ & 5.9 & 3.2 & $\mathrm{~N}$ & $\mathrm{~N}$ & $\mathrm{~N}$ & - & - \\
\hline 7 & M & 10.5 & 8.0 & $\mathrm{~N}$ & $\mathrm{~N}$ & $\mathrm{~A}(4.8 \mathrm{~mm})$ & - & - \\
\hline \multicolumn{9}{|c|}{ Group B } \\
\hline 1 & M & 15.1 & 14.5 & OMI, S, CV & $\mathrm{A}(8.0 \mathrm{~mm})$ & $\mathrm{N}$ & $\mathrm{RCA}$ & - \\
\hline 2 & M & 14.8 & 13.7 & $\mathrm{~A}(5.5 \mathrm{~mm})$ & OMI, S, RC & S & RCA, LAD, LCx & LAD \\
\hline 3 & M & 15.1 & 11.3 & OMI, S, PBP & OMI, S, PBP & A $(6.7 \mathrm{~mm})$ & RCA, LAD & RCA, LAD \\
\hline 4 & M & 16.1 & 14.4 & $\begin{array}{l}\mathrm{S} \text { and } 2 \mathrm{~A} \\
(6.2 / 7.1 \mathrm{~mm})\end{array}$ & $\begin{array}{l}\mathrm{S} \text { and } 2 \mathrm{~A} \\
(7.3 / 11.4 \mathrm{~mm})\end{array}$ & $\mathrm{N}$ & RCA, LAD, LCx & - \\
\hline
\end{tabular}

RCA, right coronary artery; LAD, left anterior descending branch; LCx, left circumflex branch; E\&D, early and delayed; PD, perfusion defect; CT, coronary territory; N, normal; A, aneurysm (maximum diameter); S, stenosis; OMI, old myocardial infarction; CV, collateral vessel formation; PBP, post bypass operation; $\mathrm{RC}$, recanalization; -, negative finding.

Figure 2 shows the bull's-eye maps of the uptake in exercise-stressed and rest ${ }^{201} \mathrm{Tl}$ imaging and early and delayed ${ }^{123}$ I-MIBG imaging of a control subject and a patient in group B. The area with ${ }^{123} \mathrm{I}-\mathrm{MIBG}$ defect was significantly larger than that with perfusion defect in the patient.

Concordance of ${ }^{201} \mathrm{Tl}$ and ${ }^{123} \mathrm{I}-\mathrm{MIBG}$ findings in the patients with $K D$. The coronary territories with myocardial perfusion defects and ${ }^{123} \mathrm{I}-\mathrm{MIBG}$ defects are shown in Table 2. Significant discordance between the coronary territories with perfusion defects and those with ${ }^{123} \mathrm{I}$-MIBG defects was found in group $\mathrm{B}(p<0.05)$ but not in group A.

\section{DISCUSSION}

$\mathrm{KD}$ is a leading cause of acquired heart disease in children $(3,34)$. According to the cohort study by Kato et al. (1), coronary aneurysm occurred in $25 \%$ of patients with acute $\mathrm{KD}$, $55 \%$ of whom showed regression. During the follow-up, ischemic heart disease developed in $4.7 \%$, myocardial infarction in $1.9 \%$, and death in $1.8 \%$.

In the KD patient, although the involvement of coronary artery is a main sequela, little is known so far concerning the impairment of CSNF. Therefore, we carried out the present study to investigate the CSNF and its relation with myocardial perfusion in KD patients. Our study found that CSNF was significantly damaged in the KD patients with coronary artery stenosis and/or history of myocardial infarction.

All coronary territories in group A had no myocardial perfusion defect, and only one coronary territory had slight ${ }^{123}$ I-MIBG defect, indicating that myocardial perfusion and CSNF were kept well in the KD patients without present or

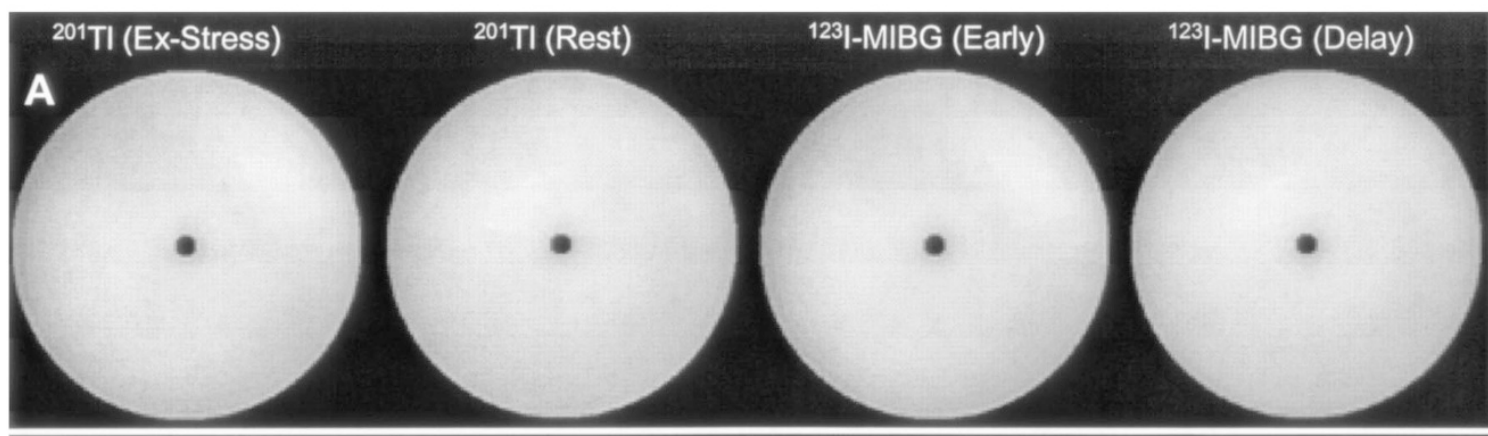

$100 \%$

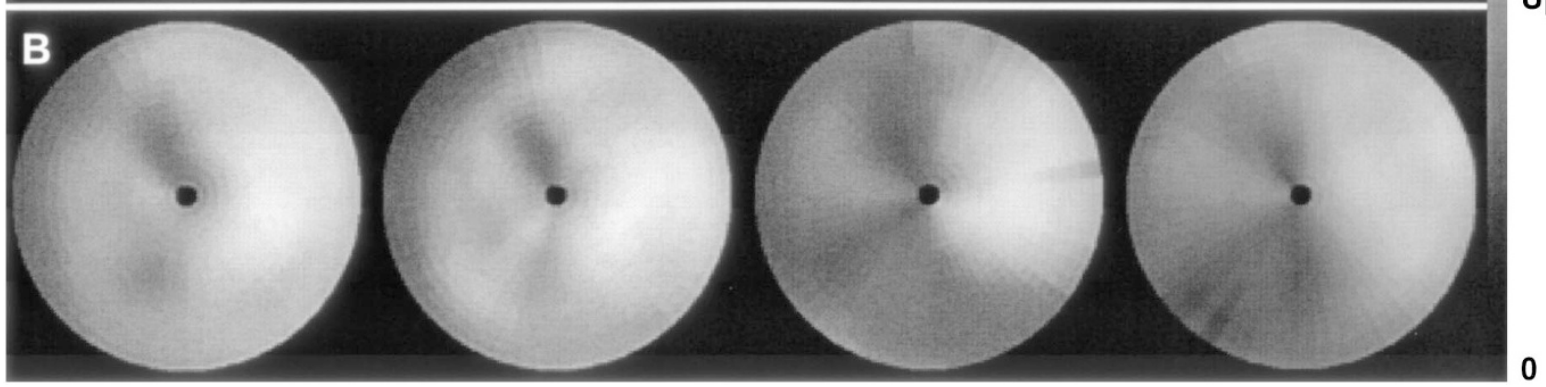

Uptake

Figure 2. Bull's-eye maps of stressed and rest ${ }^{201} \mathrm{Tl}$ uptake and early and delayed ${ }^{123} \mathrm{I}-\mathrm{MIBG}$ uptake of a 5-y-old control boy (A) and a $14-\mathrm{y}$-old boy with Kawasaki disease in group B $(B)$. In the patient, the area with ${ }^{123} \mathrm{I}-\mathrm{MIBG}$ defect is significantly larger than that with ${ }^{201} \mathrm{Tl}$ defect. 
Table 2. Concordance of the coronary territories with ${ }^{123} I-M I B G$ defect and those with perfusion defect in patients with KD

\begin{tabular}{|c|c|c|c|c|c|c|}
\hline & \multicolumn{6}{|c|}{ Coronary territories with ${ }^{123} \mathrm{I}-\mathrm{MIBG}$ defect } \\
\hline & Yes & No & Total & Yes & No & Total \\
\hline Yes & 0 & 0 & 0 & 3 & 0 & 3 \\
\hline No & 1 & 20 & 21 & 6 & 3 & 9 \\
\hline Total & 1 & 20 & 21 & 9 & 3 & 12 \\
\hline
\end{tabular}

past coronary artery stenosis. Among five coronary territories without present or past stenosis in group B, no coronary territory was found with perfusion defect and two coronary territories were found with ${ }^{123}$ I-MIBG defects. There were a total of six coronary territories with aneurysm but without stenosis in groups A and B. However, only two of them were found with ${ }^{123}$ I-MIBG defect. Considering that the occurrence of ${ }^{123}$ I-MIBG defect was not in good accordance with aneurysm, coronary aneurysm alone seemed not to be closely associated with the impairment of CSNF in patients with KD.

As opposed to the excellent concordance between the findings in ${ }^{201} \mathrm{Tl}$ and ${ }^{123} \mathrm{I}-\mathrm{MIBG}$ studies in group $\mathrm{A}$, the coronary territories with ${ }^{123} \mathrm{I}-\mathrm{MIBG}$ defects were significantly more than those with perfusion defects in group B. Fewer perfusion defects compared with ${ }^{123} \mathrm{I}-\mathrm{MIBG}$ defects found in group B suggested that even if myocardial perfusion recovered or was improved by either the formation of coronary collateral branches or re-perfusion therapy, the impairment of CSNF still remained. Cardiac adrenergic tissue is very sensitive to ischemia (35,36). Myocardial ischemia could promote denervation in the area surrounding ischemic lesions, and sympathetic nerve is thought to be more susceptible than cardiac muscle cell to permanent ischemic damage (31). In CAD patients after percutaneous transluminal coronary angioplasty, although partial re-innervation could be seen sometimes in the area with well patent coronary artery, ${ }^{123}$ I-MIBG defect remained wider than the ischemia-induced or scar-associated perfusion defect (37). Considering the finding of more ${ }^{123}$ I-MIBG defects than perfusion defects and the histories of the patients in group B, the impairment of CSNF in KD patients, likely sharing the same mechanism as that in the adult patients with CAD, is subsequent to the ischemia caused by the formation of coronary artery stenosis.

We noticed that three coronary territories with ${ }^{123} \mathrm{I}-\mathrm{MIBG}$ defects but without perfusion defect in our patients had neither present nor past coronary artery stenosis. Because sympathetic nerve is very sensitive to ischemia and might be more susceptible to cardiac muscle cell $(31,35,36)$, the ${ }^{123} \mathrm{I}-\mathrm{MIBG}$ defects in these coronary territories may reflect slight or latent ischemia, although reduced myocardial perfusion could not be detected presently. The speculation that ${ }^{123} \mathrm{I}-\mathrm{MIBG}$ imaging is capable of detecting early staged or latent ischemia in $\mathrm{KD}$ patients needs to be verified by further investigation and the data of follow-up.

Compared with most patients in group A, patients in group $\mathrm{B}$ had long KD histories (range, 11.3-14.5 y). Although a patient in group $\mathrm{A}$ also had a long KD history of $8 \mathrm{y}$, the patient showed neither perfusion nor ${ }^{123} \mathrm{I}-\mathrm{MIBG}$ defect. Therefore, it is hard to say whether the length of KD history, if without accompanying stenosis, may directly affect CSNF.

Limitations of the study. The resolution of our imaging system is $9.6 \mathrm{~mm}$ FWHM for $100-\mathrm{mm}$ radius of rotation. Because the FWHM in an ordinary myocardial SPECT study is $\sim 15 \mathrm{~mm}$ (38), the resolution of our system is thought to be sufficient for imaging myocardium in most patients. In pediatric patients with small hearts, although quantification of electrocardiographically gated SPECT has been considered to be inaccurate (38), qualitative assessment of myocardial perfusion has been considered with no special problem and generally applied in pediatric KD patients (10-15). In addition, to improve the image quality in three infantile patients in the study, a smaller radius of camera and noncircular orbit were used in the data acquisition by referring to the reported method (38).

In this study, the defects of ${ }^{201} \mathrm{Tl}$ and ${ }^{123} \mathrm{I}-\mathrm{MIBG}$ were arbitrarily defined as $<60 \%$ of the highest LV uptake. According to this criterion, perfusion abnormalities were found in only two patients in group B. However, in previous studies of Fu et al. (13) and Paridon et al. (16), a high incidence of perfusion defect was found by visual evaluation in KD patients. In our study, a slightly decreased uptake but still $>60 \%$ of the highest LV uptake was recognized as normal perfusion, whereas it might be determined as perfusion defect in their visual evaluation. Therefore, our criterion may underestimate the perfusion abnormality to some extent compared with their visual evaluation. However, because the same criterion was used in ${ }^{123} \mathrm{I}$ MIBG imaging as well in this study, the influence of the underestimation on the tracers' uptake might be counteracted between ${ }^{201} \mathrm{Tl}$ and ${ }^{123} \mathrm{I}-\mathrm{MIBG}$ studies.

Because ${ }^{123}$ I-MIBG imaging has not been used routinely in children with KD, only 11 patients were enrolled in this study. The small amount of the subjects might inevitably bring statistical uncertainness. Although our data were somewhat insufficient, the results seemed to be valuable for the understanding of the pathophysiology of KD from a new point of view.

Clinical implication. Our study found that CSNF was impaired in KD patients with coronary stenosis and/or myocardial infarction and suggested that the impairment of CSNF might be subsequent to the coronary artery stenosis in the patient with KD. In KD patients, ${ }^{123} \mathrm{I}-\mathrm{MIBG}$ defect seemed to be clear evidence of sympathetic denervation after not only present but also past ischemia or infarction, as found in CAD patients (39). 
Miyagawa et al. (18) reported that the perfusion study could provide more accurate prognosis than CAG in the patient with KD. However, the prognostic value of ${ }^{123}$ I-MIBG imaging in $\mathrm{KD}$ patients is unknown so far.

In this first-step investigation on CNSF in KD patients, because of the small amount of the patients and the lack of follow-up data, the relationship between the clinical manifestation and the impairment of CSNF is hard to be clarified for many aspects. The clinical significance of ${ }^{123} \mathrm{I}-\mathrm{MIBG}$ imaging in KD patients, such as its prognosis value, remains to be investigated.

\section{CONCLUSION}

Our preliminary study suggested that in the patients with $\mathrm{KD}$, the impairment of CSNF might be subsequent to the formation of coronary artery stenosis. In KD patients with significant coronary artery stenosis and/or history of myocardial infarction, the impairment of CSNF was more severe than that of myocardial perfusion.

\section{REFERENCES}

1. Kato H, Sugimura T, Akagi T, Sato N, Hashino K, Maeno Y, Kazue T, Eto G, Yamakawa R 1996 Long-term consequences of Kawasaki disease. A 10- to 21-year follow-up study of 594 patients. Circulation 94:1379-1385

2. Faller DV 1996 Diseases of lymph nodes and spleen. In: Bennett JC, Plum F (eds) Cecil Textbook of Medicine. W.B. Saunders, Philadelphia, pp 968-974

3. Rowley AH, Shulman ST 1999 Kawasaki syndrome. Pediatr Clin North Am 46:313329

4. Fujiwara H, Hamashima Y 1978 Pathology of the heart in Kawasaki disease. Pediatrics 61:100-107

5. Kato H, Koike S, Yamamoto M, Ito Y, Yano E 1975 Coronary aneurysms in infants and young children with acute febrile mucocutaneous lymph node syndrome. J Pediatr 86:892-898

6. Allen SW, Shaffer EM, Harrigan LA, Wolfe RR, Glode MP, Wiggins JW 1992 Maximal voluntary work and cardiorespiratory fitness in patients who have had Kawasaki syndrome. J Pediatr 121:221-225

7. Paridon SM, Ross RD, Kuhns LR, Pinsky WW 1990 Myocardial performance and perfusion during exercise in patients with coronary artery disease caused by Kawasak disease. J Pediatr 116:52-56

8. Hamaoka K, Onouchi Z, Kamiya Y, Sakata K 1998 Evaluation of coronary flow velocity dynamics and flow reserve in patients with Kawasaki disease by means of a Doppler guide wire. J Am Coll Cardiol 31:833-840

9. Schillaci O, Lagana B, Danieli R, Gentile R, Tubani L, Baratta L, Scopinaro F 1999 Technetium-99m sestamibi single-photon emission tomography detects subclinical myocardial perfusion abnormalities in patients with systemic lupus erythematosus. Eur J Nucl Med 26:713-717

10. Kondo C, Hiroe M, Nakanishi T, Takao A 1989 Detection of coronary artery stenosis in children with Kawasaki disease. Usefulness of pharmacologic stress 201Tl myocardial tomography. Circulation 80:615-624

11. Spielmann RP, Nienaber CA, Hausdorf G, Montz R 1987 Tomographic myocardial perfusion scintigraphy in children with Kawasaki disease. J Nucl Med 28:1839-1843

12. Jan SL, Hwang B, Fu YC, Lee PC, Kao CH, Liu RS, Chi CS 2000 Comparison of 201Tl SPET and treadmill exercise testing in patients with Kawasaki disease. Nucl Med Commun 21:431-435

13. Fu YC, Kao CH, Hwang B, Jan SL, Chi CS 2002 Discordance between dipyridamole stress Tc-99m sestamibi SPECT and coronary angiography in patients with Kawasaki disease. J Nucl Cardiol 9:41-46

14. Fukuda T, Ishibashi M, Yokoyama T, Otaki M, Shinohara T, Nakamura Y, Miyake T, Kudoh T, Oku H 2002 Myocardial ischemia in Kawasaki disease: evaluation with dipyridamole stress technetium 99m tetrofosmin scintigraphy. J Nucl Cardiol 9:632637

15. Schillaci O, Banci M, Scopinaro F, Tavolaro R, Villotti G, De Vincentis G, Ventriglia F, Borgia MC, Colella AC, Colloridi V 1995 Myocardial scintigraphy with 99mTcsestamibi in children with Kawasaki disease. Angiology 46:1009-1014

16. Paridon SM, Galioto FM, Vincent JA, Tomassoni TL, Sullivan NM, Bricker JT 1995 Exercise capacity and incidence of myocardial perfusion defects after Kawasaki disease in children and adolescents. J Am Coll Cardiol 25:1420-1424

17. Fukazawa M, Fukushige J, Takeuchi T, Narabayashi H, Igarashi H, Hijii T, Ueda K, Kuwabara Y, Otsuka M, Ichiya Y 1993 Discordance between thallium-201 scintig- raphy and coronary angiography in patients with Kawasaki disease: myocardial ischemia with normal coronary angiogram. Pediatr Cardiol 14:67-74

18. Miyagawa M, Mochizuki T, Murase K, Tanada S, Ikezoe J, Sekiya M, Hamamoto K, Matsumoto S, Niino M 1998 Prognostic value of dipyridamole-thallium myocardial scintigraphy in patients with Kawasaki disease. Circulation 98:990-996

19. Valette H, Syrota A 1998 Nuclear techniques in the assessment of myocardial innervation. In: Murry IPC, Ell PJ (eds) Nuclear Medicine in Clinical Diagnosis and Treatment. Churchill Livingstone, Edinburgh, pp 1525-1529

20. Wieland DM, Brown LE, Tobes MC, Rogers WL, Marsh DD, Mangner TJ, Swanson DP, Beierwaltes WH 1981 Imaging the primate adrenal medulla with [123I] and [131I] meta-iodobenzylguanidine: concise communication. J Nucl Med 22:358-364

21. Jaques S Jr, Tobes MC, Sisson JC, Baker JA, Wieland DM 1984 Comparison of the sodium dependency of uptake of meta-iodobenzylguanidine and norepinephrine into cultured bovine adrenomedullary cells. Mol Pharmacol 26:539-546

22. Atsumi H, Takeishi Y, Fujiwara S, Tomoike H 1998 Cardiac sympathetic nervous disintegrity is related to exercise intolerance in patients with chronic heart failure. Nucl Med Commun 19:451-456

23. Murata K, Sumida Y, Murashima S, Matsumura K, Takeda H, Nakagawa T, Shima T 1996 A novel method for the assessment of autonomic neuropathy in type 2 diabetic patients: a comparative evaluation of 123I-MIBG myocardial scintigraphy and power spectral analysis of heart rate variability. Diabet Med 13:266-272

24. Iwasa K, Nakajima K, Yoshikawa H, Tada A, Taki J, Takamori M 1998 Decreased myocardial 123I-MIBG uptake in Parkinson's disease. Acta Neurol Scand 97:303306

25. Murata K, Kusachi S, Murakami T, Nogami K, Murakami M, Hirohata S, Tominaga Y, Komatsubara I, Tsuji T 1997 Relation of iodine-123 metaiodobenzylguanidine myocardial scintigraphy to endomyocardial biopsy findings in patients with dilated cardiomyopathy. Clin Cardiol 20:61-66

26. Ueda T, Kusachi S, Yamaji H, Morishita N, Mima T, Imai M 1997 Recovery of iodine-123 metaiodobenzylguanidine uptake associated with left ventricular functional recovery in a patient with dilated cardiomyopathy. Endomyocardial histological findings before and after the improvement of uptake. Jpn Heart J 38:145-150

27. Yoshimura N, Kimura M, Ozaki T, Takahashi N, Sakai K 1998 [Two patients with hypertrophic cardiomyopathy showing regionally increased washout of 123I-MIBG from the thick myocardium]. Kaku Igaku 35:315-320

28. Stanton MS, Tuli MM, Radtke NL, Heger JJ, Miles WM, Mock BH, Burt RW, Wellman HN, Zipes DP 1989 Regional sympathetic denervation after myocardial infarction in humans detected noninvasively using I-123-metaiodobenzylguanidine. J Am Coll Cardiol 14:1519-1526

29. McGhie AI, Corbett JR, Akers MS, Kulkarni P, Sills MN, Kremers M, Buja LM, Durant-Reville M, Parkey RW, Willerson JT 1991 Regional cardiac adrenergic function using I-123 meta-iodobenzylguanidine tomographic imaging after acute myocardial infarction. Am J Cardiol 67:236-242

30. Ishida Y, Maeno M, Hirose Y, Takahashi N, Katabuchi T, Oka H, Hayashida K, Takamiya M, Nonogi H, Miyatake K, et al. 1995 [Characteristics of regional sympathetic dysfunction in acutely ischemic myocardium assessed by 123Imetaiodobenzylguanidine imaging: impairment of myocardial norepinephrine uptake or retention]. Kaku Igaku 32:631-642

31. Matsuo S, Takahashi M, Nakamura Y, Kinoshita M 1996 Evaluation of cardiac sympathetic innervation with iodine-123-metaiodobenzylguanidine imaging in silent myocardial ischemia. J Nucl Med 37:712-717

32. Cerqueira MD, Weissman NJ, Dilsizian V, Jacobs AK, Kaul S, Laskey WK, Pennell DJ, Rumberger JA, Ryan T, Verani MS; American Heart Association Writing Group on Myocardial Segmentation and Registration for Cardiac Imaging 2002 Standardized myocardial segmentation and nomenclature for tomographic imaging of the heart. A statement for healthcare professionals from the Cardiac Imaging Committee of the Council on Clinical Cardiology of the American Heart Association. J Nucl Cardiol 9:240-245

33. 1998 Radiation dose to patients from radiopharmaceuticals (addendum 2 to ICRP publication 53). Ann ICRP 28:1-126

34. Taubert KA, Rowley AH, Shulman ST 1994 Seven-year national survey of Kawasaki disease and acute rheumatic fever. Pediatr Infect Dis J 13:704-708

35. Hartikainen J, Mustonen J, Kuikka J, Vanninen E, Kettunen R 1997 Cardiac sympathetic denervation in patients with coronary artery disease without previous myocardial infarction. Am J Cardiol 80:273-277

36. Simula S, Vanninen E, Viitanen L, Kareinen A, Lehto S, Pajunen P, Syvanne M, Kuikka J, Laakso M, Hartikainen J 2002 Cardiac adrenergic innervation is affected in asymptomatic subjects with very early stage of coronary artery disease. J Nucl Med $43: 1-7$

37. Guertner C, Klepzig H Jr, Maul FD, Hartmann A, Lelbach S, Hellmann A, Hoer G 1993 Noradrenaline depletion in patients with coronary artery disease before and after percutaneous transluminal coronary angioplasty with iodine-123 metaiodobenzylguanidine and single-photon emission tomography. Eur J Nucl Med 20:776-782

38. Nakajima K, Taki J, Higuchi T, Kawano M, Taniguchi M, Maruhashi K, Sakazume S, Tonami N 2000 Gated SPET quantification of small hearts: mathematical simulation and clinical application. Eur J Nucl Med 27:1372-1379

39. Dae MW, Herre JM, O’Connell JW, Botvinick EH, Newman D, Munoz L 1991 Scintigraphic assessment of sympathetic innervation after transmural versus nontransmural myocardial infarction. J Am Coll Cardiol 17:1416-1423 